\author{
A - preparing concepts \\ $\mathrm{B}$ - formulating methods \\ $\mathrm{C}$ - conducting research \\ $\mathrm{D}$ - processing results \\ E - interpretation \\ and conclusions \\ $\mathrm{F}$ - editing the final \\ version
}

\section{Match performance in Polish amputee soccer Extra Ligue - a pilot study}

\author{
Agnieszka Magdalena Nowak*A-F (iD)
}

Faculty of Rehabilitation, Józef Piłsudski University of Physical Education, Warsaw, Poland

Correspondence: Agnieszka Magdalena Nowak; Józef Piłsudski University of Physical Education, Marymoncka 34, 00-968 Warsaw, Poland; email: agny.nowak@ gmail.com

\title{
Abstract
}

Introduction: The purpose of this pilot study was to determine match performance in AS considering playing positions, two halves, and playing time.

Material and methods: Twelve amputee soccer players were monitored for two days during the tournament of Polish Extra Ligue. The match performance data and heart rate (HR) response were collected from 4 matches (lasted $2 \times 20 \mathrm{~min}$ ) by Polar Team Pro. Gathered data included HR parameters, time in HRmax zones, speed, covered distance, and speed zones. Differences between two halves, 6-10 min vs. above 10 min playing time, and playing positions were assessed.

Results: There were not statistically differences between two halves in HR response, percentage of time in HRmax zones, speed, distance, and percentage of time in speed zones (except III HRmax zone). Significantly higher heart rate reserve and HRmax values, and total cover distance were observed in the longer playing time. Goalkeepers had significantly lower results than other players. Midfielders and defenders were similar in terms of HR response and percentage of time spent in HRmax zones. Strikers spent significantly more percentage of time in high-intensity running zone than other players.

Conclusions: These results brought a new knowledge to amputee soccer coaches and players about significant differences in match load relating to playing position as well as playing time. This knowledge can be beneficial in planning amputee soccer training as well as preparing special physical fitness tests corresponding to real effort during a game.

\section{Keywords: motion analysis, Match Analysis, physically disabled, match intensity, disability} sport

\section{Introduction}

Amputee soccer (AS; amputee football) is a variation of 11-a-side soccer but dedicated for individuals with limb impairments [1]. The rules are similar to regular
11 players soccer games with some exceptions, e.g. a match is played in two halves for $25 \mathrm{~min}$ with $10 \mathrm{~min}$ halftime, seven players per team. The field is smaller with dimensions $60 \times 40 \mathrm{~m}$ and goal areas measuring $8 \times 10 \mathrm{~m}$ [1]. Players have lower limb impairments and 
move in the field using forearm crutches, whereas goalkeepers have upper limb impairments and have to keep the impaired limb close to the body, under the jersey (there is a special technic of bandaging impaired upper limb to the trunk). The artificial limbs and prosthetics must be removed before the game. Using the stump and crutches to control or to direct a ball as well as slide tackles are not permitted. Player substitutions are allowed with returns. The offside rule does not apply, and goalkeepers have to remain within the goal area [1].

AS match performance has not been widely studied, but match performance is widely investigated in regular soccer. Total distance and time spent in various speed zones, especially in the high-intensity running zone (HIR) and very high-intensity zone (VHIR) regarding first and second half of the match, playing position, ball possession and skill performance, team success, time periods analyses, type of sprint activity were studied [2-7]. HIR and VHIR in soccer take about $12 \%$ of the total distance covered and it was reported that these activities are decisive in winning the ball, rapid direction changes, accelerations [4]. Researches noted that apart from playing position, HIR activities are important to overall team success $[5,6]$ and it was suggested that elite soccer is characterized by the players' ability to perform high-intensity work repeatedly [2]. HIR is consisted of moderate speed running (14.0-19.8 km/h $[4,5,7]$ or $15.0-18.0 \mathrm{~km} / \mathrm{h}[2])$ and/or high-speed running (19.8-25.2 [4-6] or $18.0-30.0 \mathrm{~km} / \mathrm{h}$ [2]) and/or sprinting (above $23.0 \mathrm{~km} / \mathrm{h}$ [3] or above $25.1 \mathrm{~km} / \mathrm{h} \mathrm{[4,5]}$ or above $30 \mathrm{~km} / \mathrm{h} \mathrm{[2]).} \mathrm{It} \mathrm{was} \mathrm{measured} \mathrm{that} \mathrm{most} \mathrm{of}$ the activities (between 58.2-85.4\% of time) in soccer are low-intensity activities (walking and jogging (speed $0-8 \mathrm{~km} / \mathrm{h} \mathrm{[2],} \mathrm{0-11} \mathrm{km/h} \mathrm{[3],} \mathrm{0-14.4} \mathrm{km/h} \mathrm{[6])).}$

Match performance was investigated in a few studies in AS $[8,9]$. The Global Positioning System (GPS) accelerometers and heart rate (HR) monitors were used to measure total distance, time in speed zones, speed, and HR. Rating of perceived exertion (RPE) and muscular fatigue pre- and post-game were investigated and were assessed in terms of playing positions during the first and the second half of match $[8,9]$. In the first study, speed zones were calculated according to gaussian curve and HIR was above $13.3 \mathrm{~km} / \mathrm{h}$ (including high speed such as $13.3-16.8 \mathrm{~km} / \mathrm{h}$ and very high speed above 16.9 $\mathrm{km} / \mathrm{h}$ ) and determined VHIR as speed above $16.9 \mathrm{~km} / \mathrm{h}$. It was found that time spent in VHIR was about 5\% [8]. In the second study, speed zones were calculated based on other studies about young able-bodied soccer and researched comfort walking speed in amputees. HIR consisted of high-speed running $(13-18 \mathrm{~km} / \mathrm{h})$ and sprinting (above $18 \mathrm{~km} / \mathrm{h}$ ). Authors did not consider VHIR [9], however they noted that AS players were often walking on crutches $(0.4-5 \mathrm{~km} / \mathrm{h})$ and spent most of the time $(53 \%)$ moving in the moderate speed zone $(9.6-$ $13.2 \mathrm{~km} / \mathrm{h}$ ), but in HIR (above $13 \mathrm{~km} / \mathrm{h}$ ) about $1.5 \%$ of a game time [9]. Furthermore, in the literature there were found differences in the total cover distance by AS players in a match: $5.65 \pm 1.07 \mathrm{~km}$ [8] or $2.98 \pm 0.56$ km [9] vs. non amputated players cover about $11 \mathrm{~km}$ per match $[3,7]$.

Concerning HR response, players load in a match is observed in five HR zones (Zone I-Zone V). Moderate exercise intensity is between $50 \%$ to $70 \%$ of maximum heart rate $\left(\mathrm{HR}_{\max }\right)$ (Zone I, II) and vigorous exercise intensity is between $70 \%$ to $85 \%$ of $\mathrm{HR}_{\max }$ (Zone III, IV) [10]. Studies reported that AS players are most of the time in a match in high intensity $\mathrm{HR}_{\max }$ zones (i.e. $64.1 \%$ of a game time AS players spent in the $\mathrm{V}$ $\mathrm{HR}_{\max }$ zone $\left(>95 \% \mathrm{HR}_{\max }\right)[9]$ and their mean heart rate $\left(\mathrm{HR}_{\text {mean }}\right.$ ) was set on $176.8 \mathrm{bpm}$ (it was $96.3 \% \mathrm{HR}_{\text {max }}$ of study group) [9]. In other study, authors observed that AS players' $\mathrm{HR}_{\text {mean }}$ was $153 \mathrm{bpm}$ and $\mathrm{HR}_{\text {max }}$ was 179 bpm and it corresponded to $81-96 \% \mathrm{HR}_{\max }$ [8]. Based on this information, AS players during a match have more than vigorous exercise intensity. Using as a baseline the reported differences from the gathered studies about AS, the topic of match performance is not clear. That is why, the purpose of this pilot study was to determine match performance in AS considering playing positions, two halves, and playing time.

\section{Material and methods}

Twelve AS players were monitored during the first tournament of Polish Extra Ligue (2019, Poland, Płońsk). Each participant has been informed about the procedures of the investigation and signed a printed consent. The study was approved by the Institutional Review Board (the Local Ethics Committees; SKE 0114/2019).

This study was performed in two consecutive days. All matches were played on the natural grass field (60 m length $\times 40 \mathrm{~m}$ width $\pm 5 \mathrm{~m}$ ) and lasted two equal periods of $20 \mathrm{~min}$ with halftime lasted for $10 \mathrm{~min}$ and no additional time (special polish rules, because each team played two matches per day). Before the tournament players completed the survey containing personal information like age, body weight, body height, training experience, playing position, type and cause of limb impairment.

The match performance data and HR response were collected from 4 matches by Polar Team Pro (Polar Team Pro, Kempele, Finland). Before the first match started, Polar HR sensor was attached to a chest strap. The final device operation was tested during warm up. The distance and activities data were collected using 
an integrated GPS system. HR frequency was coded at 1-s registration intervals. The distance covered for each speed zones and time spend in each $\mathrm{HR}_{\max }$ zones were recorded. Inactive times such as 1-minute time outs were marked in the software. Every situation such as start and end of the match, entrance and leaving the field, substitutions, injuries, a half-time break were marked in the Polar Team Pro software.

After the second match each day, data was downloaded to the computer and synchronized with system. Periods consisting of more than $5 \mathrm{~min}$ of continuous game were chosen for analyses (records). The period began when the match or the second half started, or when player entered the field after a substitution or 1-minute time out or player throwed the ball. The period ended when the match or the first half finished, or player were substituted, or 1-minute time out started.

Five speed zones (I: $3.00-6.99$ km/h, II: 7.00-10.99 $\mathrm{km} / \mathrm{h}$, III: $11.00-14.99 \mathrm{~km} / \mathrm{h}$, IV: $15.00-18.99 \mathrm{~km} / \mathrm{h}$, $\mathrm{V}$ : above $19.00 \mathrm{~km} / \mathrm{h}$ ) and five $\mathrm{HR}_{\max }$ zones (I: $50-59 \%$, II: 60-69\%, III: 70-79\%, IV: 80-89\%, and V: 90-100\%) are originally set in the Polar Team Pro software and these were used for the analysis. Time spent in each $\mathrm{HR}_{\max }$ zone and distance covered in each speed zone were calculated into percentages [\%], in relation to all time spent in a field and total distance covered. Total covered distance referred to records with time duration of more than $5 \mathrm{~min}$ and speed above $3 \mathrm{~km} / \mathrm{h}$ (because of the device limitation).

HIR was determined above $15.00 \mathrm{~km} / \mathrm{h}$ (sum of two the most demanding speed zones: IV and V) based on the literature review $[8,9]$ and options of the Polar Team Pro software.

Personal parameters such as age, body weight, body height and $\mathrm{HR}_{\text {rest }}$ values were put into the Polar Team Pro system to establish a starting point to measure HR parameters. Heart rate reserve (HRR) and the percentage heart rate reserve (\%HRR) were calculated to assess the degree of relative strain $[11,12]$. HRR is a difference between $\mathrm{HR}_{\max }$ and $\mathrm{HR}_{\text {rest }}$, where $\mathrm{HR}_{\max }$ is the highest value of HR during the analyzing game period. $\% \mathrm{HRR}$ is calculated: $\% \mathrm{HRR}=\left(\mathrm{HR}_{\text {mean }}-\mathrm{HR}_{\text {rest }}\right) /$ HRR $* 100 \%$. AS players were asked to measure rest heart rate $\left(\mathrm{HR}_{\text {rest }}\right)$ on the carotid artery for 15 seconds, after waking up, in lying position in the morning for a few days prior to the tournament began.

\section{Statistical analysis}

Statistical analyses were performed using program IBM SPSS Statistics 25. Mean, standard deviation, median, minimum, maximum, and relative difference $(\Delta \%)$ were calculated for each parameter. The Kolmogorov-Smirnov test was used to check the data distribution.
Differences between 1) first and second half, 2) playing time from 6 to $10 \mathrm{~min}$ and above $10 \mathrm{~min}, 3$ ) playing position (strikers, midfielders, defenders, goalkeepers) in terms of $\%$ of time spent in $\mathrm{HR}_{\max }$ zones and \% of distance covered in speed zones were analyzed. The U-Mann Whitney test and the T-test were used to check differences in HR, speed, and distance data between two halves (1) and playing time (2). The Kruskal-Wallis test and the one-way ANOVA with the Levene's test were used to check differences between playing positions (3). The U-Mann Whitney test was used to assess in which parameters were differences between playing position for variables. Then, post hoc tests (the Tuckey test and the Tamhane'a test) were used. The level of statistical significance was set at $p<0.05$. Effect Size (ES) as Eta square $\left[\mu^{2}\right]$ and Cohen $\mathrm{d}[d]$ were calculated [13].

Tab. 1. Effect size interpretation

\begin{tabular}{lcc}
\hline Effect size $[\mathrm{ES}]$ & Eta square $\left[\mu^{2}\right]^{\dagger}$ & Cohen $\mathrm{d}[d]^{\ddagger}$ \\
\hline Small & 0.01 & 0.2 \\
Medium & 0.06 & 0.5 \\
Large & 0.14 & 0.8 \\
\hline
\end{tabular}

$\dagger$ Effect size for the U-Mann Whitney test; $*$ Effect size for the T-test and post hoc tests

\section{Results}

Eighty-nine records of 12 players in 4 matches were analyzed (age: $29.08 \pm 5.28$ yrs., weight: $80.64 \pm 14.67 \mathrm{~kg}$, height: $178.50 \pm 7.74 \mathrm{~cm}$, training experience: $5.82 \pm 1.94$ yrs., time since impairment occurred: $19.73 \pm 9.19$ yrs.). Six players had impairment since birth and the other six had post-traumatic amputation. Three out of twelve players had upper limb impairment (goalkeepers) and nine out of twelve had lower limb impairment (field players). Forty-four records were excluded because of time duration less than $5 \mathrm{~min}$ ( $15 \%$ of active time). There were two strikers (13 records), two midfielders ( 24 records), five defenders (38 records) and three goalkeepers (13 records). Half of them $(n=6)$ were current or former players of the national team.

Total covered distance was $1804.58 \pm 386.55 \mathrm{~m}$ per match that is $45.1 \mathrm{~m} / \mathrm{min}$. Table 2 presents comparisons in HR response, speed, and distance parameters between two halves. There were not statistically differences in $\mathrm{HR}$ response, $\%$ of time in $\mathrm{HR}_{\max }$ zones, speed, distance, and $\%$ of time in speed zones (except $\%$ of time spent in III $\mathrm{HR}_{\max }$ zone). 


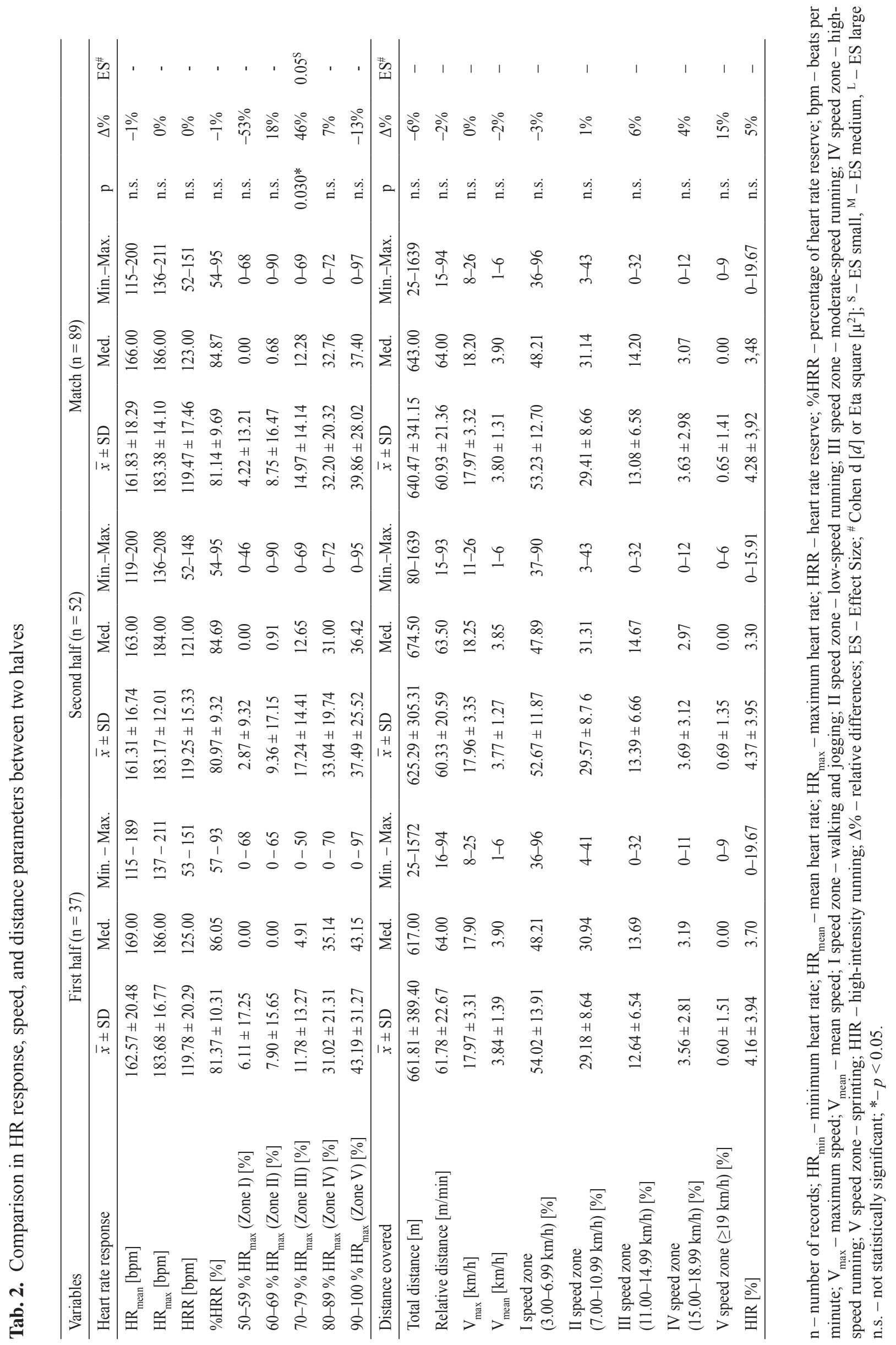


Tab. 3. Comparison in HR response, speed, and distance parameters between periods of time in AS

\begin{tabular}{|c|c|c|c|c|c|c|c|c|c|}
\hline \multirow{2}{*}{$\begin{array}{l}\text { Variables } \\
\text { Heart rate response }\end{array}$} & \multicolumn{3}{|c|}{$6-10$ min periods $(\mathrm{n}=53)$} & \multicolumn{3}{|c|}{$>10$ min periods $(n=36)$} & \multirow[b]{2}{*}{$p$} & \multirow[b]{2}{*}{$\Delta \%$} & \multirow[b]{2}{*}{$\mathrm{ES}^{\#}$} \\
\hline & $\bar{x} \pm \mathrm{SD}$ & Med. & Min.-Max. & $\bar{x} \pm \mathrm{SD}$ & Med. & Min.-Max. & & & \\
\hline $\mathrm{HR}_{\text {mean }}[\mathrm{bpm}]$ & $162.26 \pm 17.78$ & 166.00 & $115-200$ & $161.19 \pm 19.24$ & 164.00 & $115-189$ & n.s. & $-1 \%$ & - \\
\hline $\mathrm{HR}_{\max }[\mathrm{bpm}]$ & $181.53 \pm 12.86$ & 184.00 & $136-208$ & $186.11 \pm 15.53$ & 188.00 & $137-211$ & $0.013^{*}$ & $3 \%$ & $0.07^{\mathrm{M}}$ \\
\hline HRR [bpm] & $117.81 \pm 15.97$ & 121.00 & $52-148$ & $121.92 \pm 19.41$ & 126.50 & $53-151$ & $0.042 *$ & $3 \%$ & $0.05^{\mathrm{S}}$ \\
\hline$\%$ HRR [\%] & $82.77 \pm 9.18$ & 85.83 & $54-95$ & $78.73 \pm 10.03$ & 79.11 & $57-93$ & n.s. & $-5 \%$ & - \\
\hline $50-59 \% \mathrm{HR}_{\max }$ (Zone I) [\%] & $4.09 \pm 12.94$ & 0.00 & $0-68$ & $4.42 \pm 13.80$ & 0.00 & $0-62$ & n.s. & $8 \%$ & - \\
\hline $60-69 \% \mathrm{HR}_{\max }$ (Zone II) [\%] & $7.26 \pm 16.73$ & 0.16 & $0-90$ & $10.94 \pm 16.05$ & 2.42 & $0-65$ & n.s. & $51 \%$ & - \\
\hline $70-79 \% \mathrm{HR}_{\max }$ (Zone III) [\%] & $14.63 \pm 12.38$ & 12.28 & $0-53$ & $15.47 \pm 16.56$ & 11.58 & $0-69$ & n.s. & $6 \%$ & - \\
\hline $80-89 \% \mathrm{HR}_{\max }$ (Zone IV) [\%] & $35.97 \pm 20.19$ & 36.14 & $0-72$ & $26.65 \pm 19.46$ & 20.97 & $0-70$ & $0.033^{*}$ & $-26 \%$ & $0.05^{\mathrm{S}}$ \\
\hline $90-100 \% \mathrm{HR}_{\max }($ Zone V) [\%] & $38.05 \pm 25.47$ & 37.40 & $0-95$ & $42.52 \pm 31.59$ & 39.96 & $0-97$ & n.s. & $12 \%$ & - \\
\hline Distance covered & $\bar{x} \pm \mathrm{SD}$ & Med. & Min.-Max. & $\bar{x} \pm \mathrm{SD}$ & Med. & Min.-Max. & $p$ & $\Delta \%$ & $\mathrm{ES}^{\#}$ \\
\hline Total distance $[\mathrm{m}]$ & $544.62 \pm 238.37$ & 617.00 & $25-945$ & $781.58 \pm 416.90$ & 788.00 & $80-1639$ & $0.003 *$ & $44 \%$ & $0.16^{\mathrm{L}}$ \\
\hline Relative distance [m/min] & $63.92 \pm 20.38$ & 70.00 & $16-93$ & $56.53 \pm 22.29$ & 55.50 & $15-94$ & n.s. & $-12 \%$ & - \\
\hline $\mathrm{V}_{\max }[\mathrm{km} / \mathrm{h}]$ & $17.90 \pm 3.62$ & 17.90 & $8-26$ & $18.06 \pm 2.86$ & 18.35 & $12-24$ & n.s. & $1 \%$ & - \\
\hline $\mathrm{V}_{\text {mean }}[\mathrm{km} / \mathrm{h}]$ & $3.98 \pm 1.26$ & 4.30 & $1-6$ & $3.54 \pm 1.36$ & 3.50 & $1-6$ & n.s. & $-11 \%$ & - \\
\hline $\begin{array}{l}\text { I speed zone } \\
(3.00-6.99 \mathrm{~km} / \mathrm{h})[\%]\end{array}$ & $53.10 \pm 12.51$ & 48.35 & $38-96$ & $53.42 \pm 13.15$ & 47.66 & $36-87$ & n.s. & $1 \%$ & - \\
\hline $\begin{array}{l}\text { II speed zone } \\
(7.00-10.99 \mathrm{~km} / \mathrm{h})[\%]\end{array}$ & $29.58 \pm 7.95$ & 30.50 & $4-42$ & $29.16 \pm 9.73$ & 32.02 & $3-43$ & n.s. & $-1 \%$ & - \\
\hline $\begin{array}{l}\text { III speed zone } \\
(11.00-14.99 \mathrm{~km} / \mathrm{h})[\%]\end{array}$ & $12.84 \pm 6.40$ & 13.83 & $0-32$ & $13.43 \pm 6.92$ & 15.17 & $1-32$ & n.s. & $5 \%$ & - \\
\hline $\begin{array}{l}\text { IV speed zone } \\
(15.00-18.99 \mathrm{~km} / \mathrm{h})[\%]\end{array}$ & $3.75 \pm 3.05$ & 3.07 & $0-11$ & $3.46 \pm 2.90$ & 2.99 & $0-12$ & n.s. & $-8 \%$ & - \\
\hline V speed zone $(\geq 19 \mathrm{~km} / \mathrm{h})[\%]$ & $0.73 \pm 1.67$ & 0.00 & $0-9$ & $0.53 \pm 0.92$ & 0.00 & $0-4$ & n.s. & $-28 \%$ & - \\
\hline HIR [\%] & $4.48 \pm 4.21$ & 3.19 & $0-19.67$ & $3.99 \pm 3.49$ & 3.59 & $0-15.91$ & n.s. & $-11 \%$ & - \\
\hline
\end{tabular}

$\mathrm{n}$ - number of records; HRmin - minimum heart rate; HRmean - mean heart rate; HRmax - maximum heart rate; HRR - heart rate reserve; \%HRR - percentage of heart rate reserve; bpm - beats per minute; $\mathrm{V}_{\text {max }}$ - maximum speed; $\mathrm{V}_{\text {mean }}$ - mean speed; I speed zone - walking and jogging; II speed zone - low-speed running; III speed zone - moderate-speed running; IV speed zone - high-speed running; V speed zone - sprinting; HIR - high-intensity running; $\Delta \%$ - relative differences; ES - Effect Size; ${ }^{\#}$ Cohen d $[d]$ or Eta square $\left[\mu^{2}\right] ;{ }^{S}-$ ES small, ${ }^{\mathrm{M}}$ - ES medium, ${ }^{\mathrm{L}}-\mathrm{ES}$ large n.s. - not statistically significant; ${ }^{*}-p<0.05$.

Table 3 presents a comparison in HR response, speed, and distance parameters between periods of time in AS (6-10 min vs. above $10 \mathrm{~min})$. In 4 out 19 variables there were significant differences. Significantly higher HRR and $\mathrm{HR}_{\max }$ values were observed in the longer playing time. Total covered distance was significantly higher in the longer playing time (Tab. 3).

Table 4 and 5 present comparisons between playing positions and HR response, speed, and distance parameters. Goalkeepers spent the most \% of time in $\mathrm{I} \mathrm{HR}_{\max }$ zone and the least \% of time in IV and $\mathrm{V} \mathrm{HR}_{\max }$ zones in comparison to other players $(p<0.05)$. Midfielders and defenders were similar in terms of HR response and $\%$ of time spent in $\mathrm{HR}_{\max }$ zones $(p>0.05)$ (Tab. 4). In terms of playing positions, $\%$ of time spent in I speed zone statistically differed all playing positions. Goalkeepers spent in this zone most of the playing time and strikers the least of the time. Maximum speed and \% of time spent in IV speed zone did not differ midfielders and defenders. Strikers spent significantly more \% of time in IV (about 7\%) and V (about 3\%) speed zones (HIR) than other players (Tab. 5). 


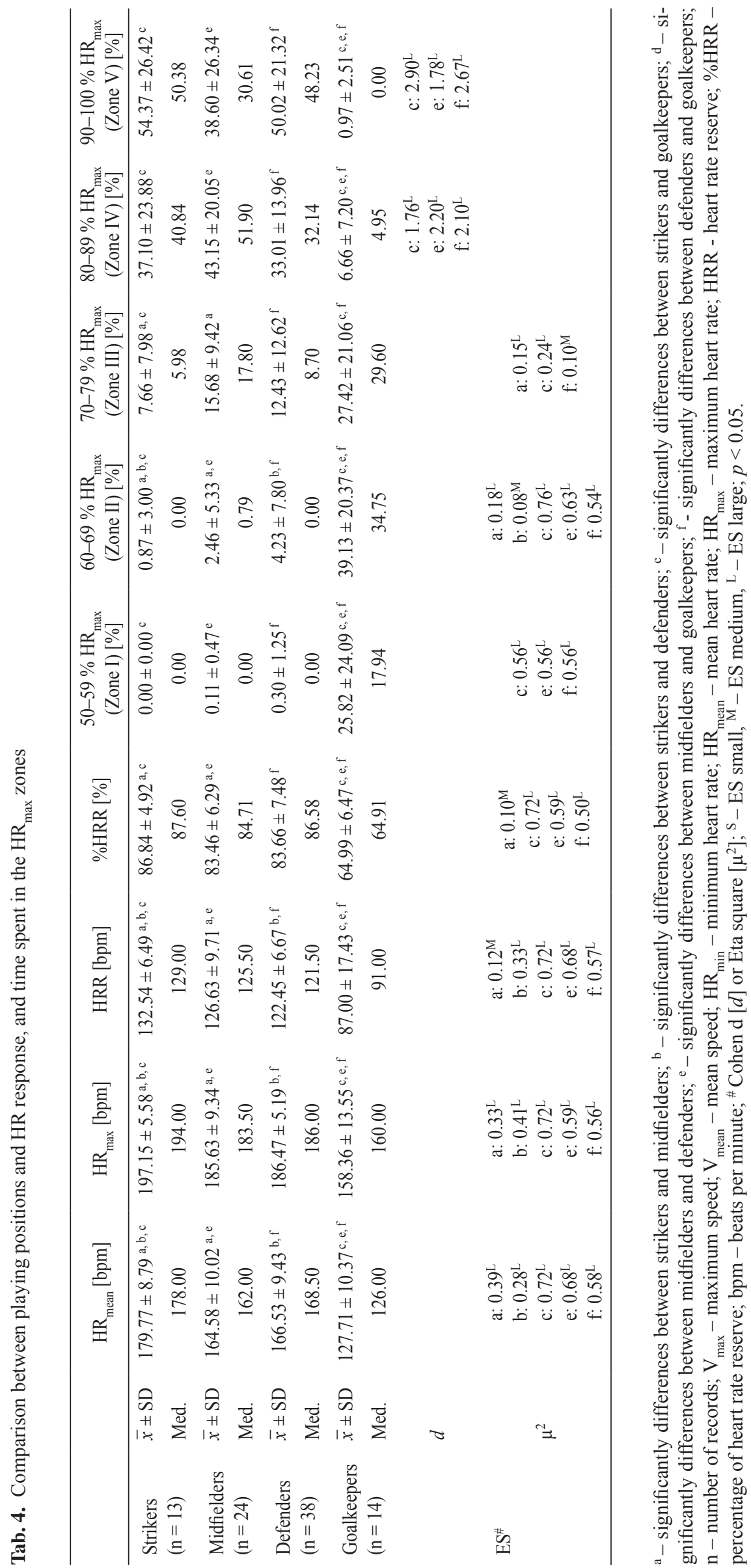




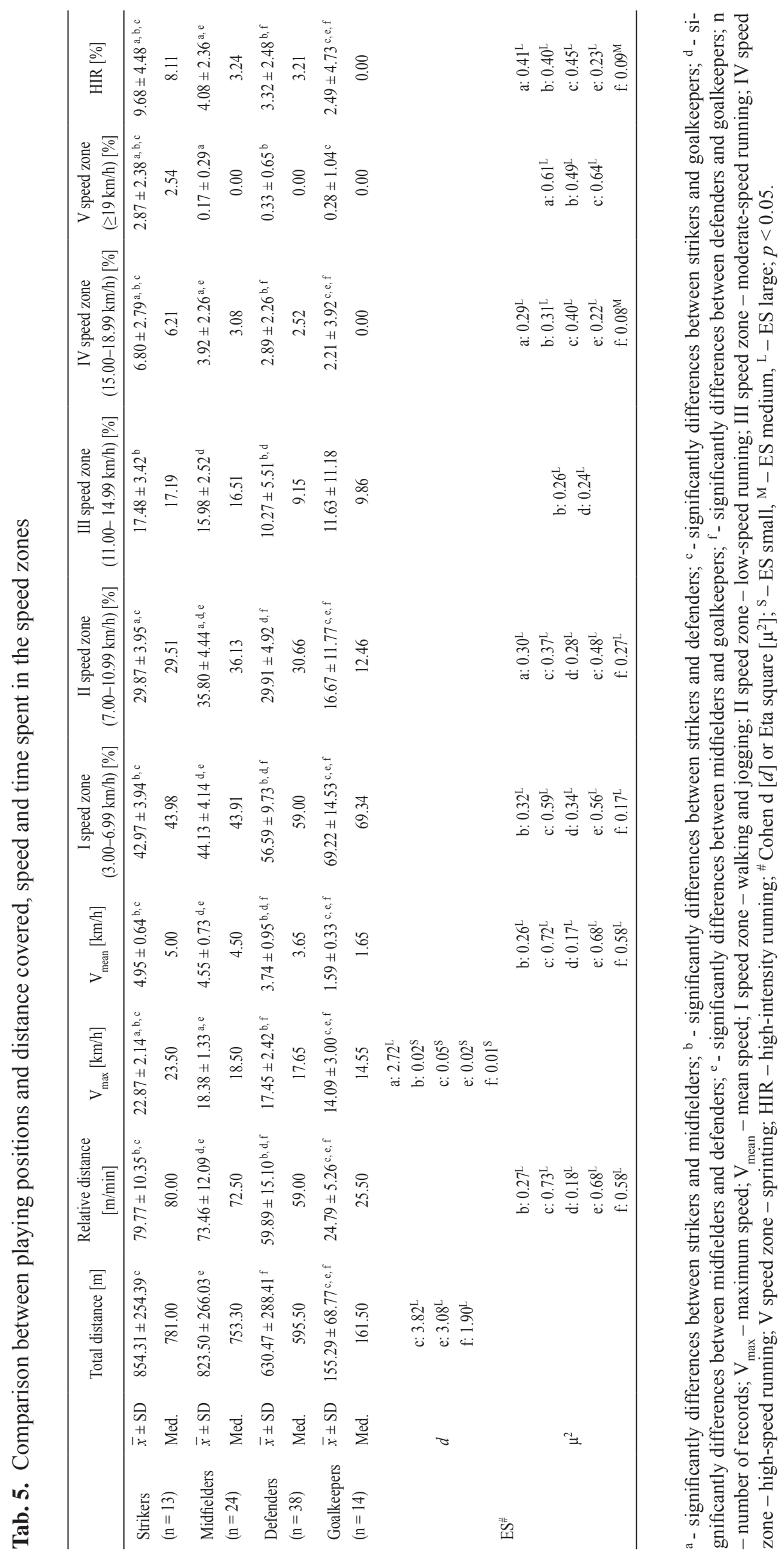




\section{Discussion}

The purpose of this pilot study was to determine match performance in AS considering playing positions, two halves, and playing time. Eighty-nine records of 12 players were chosen according to inclusion criteria such as playing time above $5 \mathrm{~min}$, in terms of $\mathrm{HR}$ response, speed, and distance parameters.

Based on our results players spent in IV and V HRmax zones average $72 \%$ of playing time. $\mathrm{HR}_{\text {mean }}$ corresponded to players' $88 \% \mathrm{HR}_{\max }$. Moreover, comparing HR response in the duration of playing time (6-10 min vs. above $10 \mathrm{~min}$ ) players' $\mathrm{HR}_{\max }$ and $\mathrm{HRR}$ were higher by $3 \%$ in the longer playing time ( $p<0.05$, small ES). It corresponds to activity in IV and $\mathrm{V} \mathrm{HR}_{\max }$ zones that match performance in IV $\mathrm{HR}_{\max }$ zone was significantly higher by $26 \%$ in the shorter time ( $p<0.05$, small ES) and activity in $\mathrm{V} \mathrm{HR}_{\max }$ zone was higher by $12 \%$ in the longer time with no significant difference. Referring to The American Heart Association [10], vigorous intensity consists of $70 \%$ to $85 \%$ of $\mathrm{HR}_{\max }$ (Zone III, IV). The observation from this study indicates that match performance in AS qualifies as more than vigorous. A similar observation was also found in other AS studies $[8,9]$. This study results presented the shorter playing time linked to higher $\mathrm{HR}_{\max }$ values and it indicated on higher intensity in match.

Mean total covered distance was higher by $44 \%$ in playing time more than $10 \min (p<0.05$, large ES) compare to 6-10 min playing time. It was not surprising that the longer time allowed to cover longer distance. However, it would be not correct to refer this distance to players, because mean total covered distance presented in this study is a distance per analyzed records (one player might have more than one record depending on his entries to the field). In this study, mean total covered distance per player was $1.80 \pm 0.39 \mathrm{~km}$ in a match that is $45 \mathrm{~m} / \mathrm{min}$. In the literature, meaningfully higher mean total covered distance was noticed: $5.65 \pm 1.07 \mathrm{~km}$ [8] or $2.98 \pm 0.56 \mathrm{~km}$ [9]. Relative distance was calculated on average $113 \mathrm{~m} / \mathrm{min}$ [8] and $60 \mathrm{~m} / \mathrm{min}$ [9], respectively. Noted differences between results from other studies and the current study, do not give clear conclusions. All currently observed matches lasted $2 \times 20 \mathrm{~min}$ and in other studies matches lasted $2 \times 25 \mathrm{~min}$ (according to the international AS rules) $[1,8,9]$. In this study all players (strikers, midfielders, defenders, and goalkeepers) were observed, in another, only outfield players [8] were analyzed or intra-positions analyze was not performed [9]. Our results of distance can be influenced by the shorter playing time and by an inclusion of goalkeepers. Goalkeepers have limited area for movement (goal area) and different game requirements. They should be analysed separately in future studies.
Another difference noted in methods between compared studies was analysed time periods. In this study short time periods (below $5 \mathrm{~min}$ ), halftime and timeouts were excluded. In other studies, all matches were analysed with additional game time if it occurred, with no information if analyses included halftime $[8,9]$. Above mentioned information may explain differences in the total covered distance. Covered distance at HIR has been identified as key performance indicators of match performance in able-bodied soccer [2] and based on our analyses we agree with other authors [9] that HIR might be also important indicator in amputee soccer. HIR (in this study $>15 \mathrm{~km} / \mathrm{h}$ ) occupied about $4 \%$ of match time (for comparison $5 \%$ for VHIR $>16.9 \mathrm{~km} / \mathrm{h}$ [8], and $1.5 \%$ for HIR $>13 \mathrm{~km} / \mathrm{h}$ [9]). We think that this result, together with high-intensity HR response, and with relatively small mean covered distance per players, indicates for AS game as extremely highly intensive. To have more complete image of AS match performance, it is recommend expanding this match performance analyses to win/lose match and actions with/without ball possession.

Considering playing positions, many significant differences between players were observed in this study. In general, all players were significantly different in $\mathrm{HR}$ response $\left(\mathrm{HR}_{\text {mean }}, \mathrm{HR}_{\max }, \mathrm{HRR}, \% \mathrm{HRR}\right)$ except midfielders vs. defenders. The highest HR response parameters were for strikers and the lowest for goalkeepers (by $82 \%$ difference). Outfield players spent similar $\%$ of time in I, IV, V $\mathrm{HR}_{\max }$ zones, only goalkeepers were significantly different than others (spending 26\% of time in $\mathrm{I} \mathrm{HR}_{\max }$ zone in comparison other players spent less than $1 \%$ in $\mathrm{I} \mathrm{HR}_{\text {max }}$ zone, strikers $0 \%$, and only about $8 \%$ of time in IV and $\mathrm{V} \mathrm{HR} \mathrm{Hax}_{\max }$ zones (large ES) in comparison to others that spent more than $80 \%$ of time in these zones). In other AS studies, $\mathrm{HR}_{\text {mean }}$ and only values above $80 \% \mathrm{HR}_{\max }$ were assessed (Zone IV and V) $[8,9]$. No differences have been found in HR response between playing positions because that information was not taken into account. Therefore, a comparison is not possible between studies.

In the current study, \% time spent in I speed zone statistically differed between positions with the most time spent by goalkeepers and least time spent by strikers. In general players spent about $53 \%$ of playing time in I speed zone by walking and jogging $(3.00-6.99 \mathrm{~km} / \mathrm{h})$ that is similar to results of other AS study ( $45 \%$ of time by walking in $0.4-5.0 \mathrm{~km} / \mathrm{h}$ such as II speed zone) [9] and in opposition to findings from another AS study (53\% of time in moderate speed zone (III) such as $9.6-13.2 \mathrm{~km} / \mathrm{h}$ and only $3 \%$ of time by $0-7 \mathrm{~km} / \mathrm{h}$ ) [8]. Based on these results, it may be suggested that AS is not very demanding game, but it is important to connect all results 
together, speed and HR response. It can be indicated that HR response and speed may show total players' involvement in the game according to their roles. Additionally, referring to the covered distance, strikers covered the biggest relative distance and it was confirmed in other findings [8]. $\mathrm{V}_{\text {max }}$ differed players, but the most noticeable difference was between strikers and goalkeepers $\left(\Delta \%=-38 \%\right.$, large ES). Mean $\mathrm{V}_{\max }$ varied from $14.1 \mathrm{~km} / \mathrm{h}$ (goalkeepers) to $22.9 \mathrm{~km} / \mathrm{h}$ (strikers) with no differences in speed between midfielders and defenders. In other study, mean $\mathrm{V}_{\max }$ was $16.1 \mathrm{~km} / \mathrm{h}$ (midfielders) [8] and was lower than this observed in our results. Because of scarce studies of AS match performance, it might be not reasonable to use the same speed zones to assess AS players from different countries or sports levels, because of their different match performance which is not only consisted of speed and covered distance but also with parameters like: ball possession, skill performance, team success, tactical aspects.

In conclusion, the current study results show many differences across playing positions and suggest that someone playing on fitting position should not be random. In future research, more variables and wider perspective should be taken into consideration to assess AS match performance.

\section{Limitations and recommendation for future studies}

One of the limitations of this study is assessment together all players despite that they have different playing roles and goalkeepers have limited place for mobility. We included goalkeepers in this study because they are usually overlooked in game performance analyses. Goalkeepers had significantly lower HR response, covered distance, and speed. We suggest not to exclude goalkeepers in future studies.

In this study result, high standard deviations in $\mathrm{HR}_{\text {max }}$ zones results were observed and there were no significant differences in these variables. This big relative differences in results might be confusing for reader.

The distance parameters were analysed according to records chosen from the Polar Team Pro and did not include speed below $3 \mathrm{~km} / \mathrm{h}$. Moreover, in connection with the selection of periods above $5 \mathrm{~min}, 15 \%$ of data were not analysed. For future studies we recommend performing more detailed analyses which can better reflect players' performance and to have clearer picture of AS match performance.

As last point, we recommend in the future studies to conduct a fuller match analysis as it is implemented in able-bodied soccer adding i.e. ball possession situations, win, or lose a match, comparing win/lose team between them, include tactical aspects.

\section{Conclusions}

In conclusion, the current study's results brought a new knowledge to AS coaches and AS players about significant differences in match load relating to players' playing position as well as playing time. This knowledge can be beneficial in planning AS training as well as preparing special physical fitness tests corresponding to real AS players' effort like HR, distance, speed during AS game.

\section{Funding}

This research received no external funding.

\section{Conflicts of interest}

The authors declare no conflict of interest.

\section{Acknowledgments}

I would like to thank all the study participants and their coaches. Especially I would like to thank my associates for valuable support and input.

\section{References}

1. Fispes.it [Internet]. World Amputee Football Federation Laws and Rules Governing Amputee Football Play and Players; 2017 [cited 2020 May 2]. Available from: https://fispes.it/kp/uploads/laws-of-the-game2017.pdf/.

2. Mohr M, Krustrup P, Bangsbo J. Match performance of high-standard soccer players with special reference to development of fatigue. J Sports Sci. $2003 \mathrm{Jul}$; 21(7): 519-28.

3. Di Salvo V, Baron R, Tschan H, Calderon Montero FJ, Bachl N, Pigozzi F. Performance characteristics according to playing position in elite soccer. Int J Sports Med. 2007 Mar; 28(3): 222-7.

4. Rampinini E, Bishop D, Marcora SM, Ferrari Bravo D, Sassi R, Impellizzeri FM. Validity of simple field tests as indicators of match-related physical performance in top-level professional soccer players. Int $\mathrm{J}$ Sports Med. 2007 Mar; 28(3): 228-35.

5. Bradley PS, Sheldon W, Wooster B, Olsen P, Boanas P, Krustrup P. High intensity running in English FA Premier League soccer matches. J Sports Sci. 2009 Jan 15; 27(2): 159-68.

6. Di Salvo V, Gregson W, Atkinson G, Tordoff P, Drust B. Analysis of high intensity activity in Premier League soccer. Int J Sports Med. 2009 Mar; 30(3): 205-12.

7. Rampinini E, Impellizzeri FM, Castagna C, Coutts AJ, Wisløff U. Technical performance during soccer matches of the Italian Serie A league: effect of fatigue 
and competitive level. J Sci Med Sport. 2009 Jan; 12(1): 227-33.

8. Simim MAM, da Mota GR, Marocolo M, da Silva BVC, de Mello MT, Bradley PS. The demands of amputee soccer impair muscular endurance and power indices but not match physical performance. APAQ. 2018 Jan 1; 35(1): 76-91.

9. Maehana H, Miyamoto A, Koshiyama K, Tanaka Yanagiya T, Yoshimura M. Profile of match performance and heart rate response in Japanese amputee soccer players. J Sports Med Phys Fitness. 2018 Jun; 58(6): 816-24.

10. mayoclinic.org [Internet]. Exercise intensity: How to measure it; 2019 [cited 2020 May 08]. Available from: https:/www.mayoclinic.org/healthy-lifestyle/fitness/ in-depth/exercise-intensity/art-20046887.
11. Janssen TW, van Oers CA, van der Woude LH, Hollander AP. Physical strain in daily life of wheelchair users with spinal cord injuries. Med Sci Sports Exerc. 1994 Jun; 26(6): 661-70.

12. Marszałek J, Gryko K, Kosmol A, Morgulec-Adamowicz N, Mróz A, Molik B. Wheelchair basketball competition heart rate profile according to players' functional classification, tournament level, game type, game quarter and playing time. Front Psychol. 2019 Apr 15; 10: 773.

13. imaging.mrc-cbu.cam.ac.uk [Internet]. Rules of thumb on magnitudes of effect sizes; 2019 [cited 2020 May 11]. Available from: http://imaging.mrc-cbu.cam. ac.uk/statswiki/FAQ/effectSize. 